\title{
Os biotecnólogos brasileiros em face da sócio e da biodiversidade
}

\author{
LAYMERT GARCIA DOS SANTOS
}

\section{RESUMO}

Este ensaio questiona o papel que os biotecnólogos têm assumido no Brasil, tanto em sua não-relação com os povos indígenas e tradicionais quanto em sua relação negativa com os ambientalistas e demais setores da sociedade civil. Se prevalecerem somente os interesses da tecnociência e do mercado, é preciso pensar desde já nos possíveis "efeitos colaterais".

PALAVRAS-CHAVE: biodiversidade; lei de biossegurança; biotecnologia; transgênicos.

\section{SUMMARY}

This essay puts into question the role played by biotechnologists in Brazil. It argues that indigenous and traditional peoples, environmentalists and also the civil society should be taken into consideration. If priorities of techno-science and market are the only ones to prevail, it's already time to think about the "collateral damage".

KEYWORDS: biodiversity; biosecurity law; biotechnology; transgenics.

Já se escreveu que o século XXI é o da biotecnologia, que vivemos na "era" da biotecnologia, que ela expressa o futuro etc. Também muito se especulou, desde o início da década de 1990, sobre a relação entre biotecnologia e biodiversidade, o que, para nós, brasileiros, faz todo sentido, tendo em vista sermos, ainda, o país mais megadiverso do planeta e podermos contar com uma certa massa crítica, em termos de biologia e de biologia molecular. Tudo isso importa, e é preciso considerar, quando se pensa em biotecnologia no Brasil. Mas há uma questão que nunca ou quase nunca entra no espectro dos cientistas brasileiros:é a presença em nosso espaço territorial de cerca de duzentos povos indígenas, em sua maior parte concentrados nas terras mais ricas em diversidade biológica, e representando cerca de 10\% da Amazônia Legal. Pois tudo se passa como se eles simplesmente não existissem, não contribuíssem em nada para a singularidade da natureza e da cultura no país, e não significassem nada para o nosso futuro científico. Assim, não seria exagero dizer que para a tecnociência, tal como praticada no Brasil, essa presença é invisível, de tão insignificante. 
Não adianta o Estado brasileiro assinar tratados internacionais que reconhecem explicitamente a importância dos povos indígenas, tais como a Resolução 169 da Organização Internacional do Trabalho, a Convenção sobre Diversidade Biológica, o Tratado Internacional sobre Recursos Fitogenéticos para a Alimentação e a Agricultura da FAO, e a Convenção sobre a Proteção e Promoção da Diversidade das Expressões Culturais. Não adianta existir uma bibliografia antropológica consistente, elaborada por profissionais competentes que já estudaram os povos contatados e inscreveram em livros muito de sua cosmologia, de sua complexa organização social, de sua arte sofisticada, em resumo, de seus conhecimentos tradicionais. Também de nada adianta constatar que abnegadas ONGs indigenistas vêm se dedicando há décadas à defesa dos interesses dos povos indígenas, mapeando a situação de territórios e aldeias, como o faz o Instituto Socioambiental, trabalhando com eles, como o CTI e a CCPY, registrando imagens, como o projeto Vídeo nas Aldeias, divulgando a cultura, a dança e a música, como o Ideti. Enfim, de nada adianta Villa-Lobos e outros terem criado a partir de sua música, Claudia Andujar e Maureen Bisilliat terem fotografado a sua beleza, Andrea Tonacci e outros terem filmado suas vidas, Mário e Oswald de Andrade terem se inspirado neles (lembrem-se de Macunaíma e da perturbadora máxima paradoxal "Tupi or not tupi, that's the question"), Montaigne ter refletido sobre a sua superioridade no tocante à liberdade. Ao que tudo indica, não há trabalho, pesquisa ou iniciativa cultural que seja capaz de romper o preconceito contra os povos indígenas e os seus saberes e de despertar um interesse genuíno por seu pensamento e suas práticas referentes a plantas, animais e todo tipo de servivo. Os anos e as décadas passam e a mentalidade continua, no fundo, a mesma dos tempos da Colônia. Não é à toa que em $1^{\circ}$. de novembro de 2002 foi publicado na seção de animais dos classificados da Folha de Boa Vista um anúncio que dizia: "Vendem-se filhotes de Yanomami com 1 ano e seis meses. R\$ 1.000,00. Tratar 99713287 ".

Não adianta. Salvo engano, ninguém no campo científico se pergunta por que as sociedades indígenas preservam, conservam e produzem florestas e nossa sociedade é incapaz de deter a sua devastação. Pior ainda: como afirma o jornalista amazônida Lúcio Flávio Pinto:

Reino da luz, da água e da floresta, a desafiar os cânones do saber criados combase em outras paisagens, a Amazôniaé - éécada vez menos - oterritório ideal para um derradeiro experimento do homem, impenitente e impertinente Homo agricola: o estabelecimento de uma civilização florestal, baseada no uso inteligente do bem mais nobre desse bioma, centrado na massa vegetal, fonte da maior biodiversidade da Terra. No entanto, eis como já
[1] " 3 '. Relatório Nacional sobre Direitos Humanos no Brasil - 20022005". São Paulo: Núcleo de Estudos da Violência, Universidade de São Paulo, 2007, p. 348 . 
[2] "Quatro décadas de destruição na Amazônia". Texto escrito para o seminário internacional "Ensaios Amazônicos", organizado por Eduardo Viveiros de Castro e Laymert Garcia dos Santos, e promovido pelo Instituto Goethe e o SESC Paulista, em São Paulo, de 8 a 10 de dezembro de 2006; a ser publicado com a contribuição dos outros palestrantes em 2008 pela Cosac Naify. ingressamosnos anais da história humana:como o povo que mais destruiuflorestas em todos os tempos. Em menos de meio século, mais de 700 mil quilômetros quadrados de floresta nativa postosabaixo. A velocidade e a amplitude dessa destruição impressionam. Em 1976 o satélite Skylab "fotografou" o maior incêndio registrado pela máquina de informação, provocando comoção internacional. Ofogaréu de quase 10 mil hectares fora provocado pela Volkswagen, que se achava no sul do Pará produzindo não veículo automotor, sua especialidade exclusiva até então, mas boi, sua "desespecialidade", para usar uma expressão neológica, que Lewis Carrol assinaria com embevecimento, dada sua aptidão para a linguagem surreal, a única que cabe à reprodução da insensatez-padrão na conquista amazônica² .

Com efeito, tudo se passa como se, para lidar com a Amazônia e a civilização florestal que ela requer, não tivéssemos nada a aprender com os povos da floresta. Como se eles não constituíssem sociedades tropicais, como se nada pensassem há milênios sobre o meio em que habitam, como se sua inteligência e sua sensibilidade fossem incapazes de avançar, de aprender, de evoluir - ao contrário, evidentemente, das nossas. Assim, aparentemente, tudo o que sabem sobre a vida em suas diferentes manifestações não teria serventia alguma para as "ciências da vida", pelo menos tal como são desenvolvidas por aqui.

Tal postura revela, por um lado, a prevalência dos velhos clichês socioculturais que os brasileiros herdaram do passado, e que os fazem desprezar ou menosprezar todo conhecimento "não-branco", ou nãoocidental; mas, por outro lado, revela também a arrogância e a autosuficiência de que se revestem, entre nós, a ciência e a tecnologia modernas. Características que, aliás, são próprias do conhecimento científico e tecnocientífico mas que, aqui, parecem se exacerbar, precisamente porque nossa debilidade (para os padrões internacionais), enquanto produtores de invenção e de inovação, gera em nossos cientistas uma hiper-sensibilidade que os faz considerar como uma atitude irracional, supersticiosa ou anticientífica, para não dizer quase criminosa, qualquer manifestação de distância crítica ou de questionamento de sua defesa incondicional do progresso como bem primordial da humanidade. Assim, em virtude de uma perspectiva evolucionista acrítica, não faz sentido dar atenção aos saberes tradicionais porque isso já significaria abrir as portas a uma contaminação que só pode conduzir a uma regressão ou, no mínimo, comprometer nosso avanço. É o que fica evidente até quando os biólogos e biotecnólogos reconhecem que o conhecimento tradicional contém, por exemplo, um saber sobre um princípio ativo; nesse caso, isola-se e extrai-se essa "informação" do contexto teórico e epistemológico no qual ela faz pleno sentido, como uma matéria-prima útil que precisasse ser libertada das crendices e superstições que a "envolvem"; na melhor das hipóteses, concede-se, na 
ocasião, que a informação coletada possui algum valor passível de ser considerado na rubrica "repartição de benefícios", preconizada pela Convenção sobre Diversidade Biológica.

Mas os cientistas brasileiros não parecem ser avessos apenas à produção de conhecimento das sociedades indígenas. Dentro de nossa própria sociedade eles resistem e parecem se opor aos setores e correntes que, mesmo não questionando o valor do conhecimento científico, pretendem problematizá-lo relacionando o desenvolvimento das novas tecnologias, sobretudo das biotecnologias, com os riscos e "efeitos colaterais" que lhes são inerentes e que precisam ser ponderados quando são feitas as opções tecnológicas. Isso ficou evidente no conflito que opôs cientistas a ambientalistas no episódio da aprovação da lei de biossegurança e na crise da CTNBio, a partir de 2003. Com efeito, o episódio e a crise explicitaram o conflito em torno da adoção ou não da agricultura transgênica no Brasil, mostrando que os cientistas são muito pouco dispostos a discutir a questão do risco, por acharem que ela pode ameaçar o desenvolvimento da ciência e da tecnologia no país.

A sociologia do risco, de Beck e outros, a sociologia da virulência, mais recentemente, e os estudos de Paul Virilio nos fizeram descobrir, primeiro, que o "risco", o "acidente" e o "efeito colateral" são parte constitutiva do progresso tecnológico, e, segundo, que a tecnociência só sabe lidar com riscos tecnológicos... propondo mais tecnologia, mais soluções tecnológicas que fazem o risco mudar de patamar. Nesse sentido, e paradoxalmente, quanto mais avança o progresso, mais avançam o risco e a incerteza 3 .

Foi em razão disso tudo que o princípio de precaução tornou-se fundamental, e objeto de uma luta política intensa nos foros internacionais durante os anos $1990^{4}$. A sociedade começou a perceber que não poderia mais deixar exclusivamente para a tecnociência a resolução dos problemas tecnocientíficos. Ora, tudo o que esta não quer é que outros, que não os especialistas, venham lhe dizer que há limites. Como o capital, que também não aceita limites para a sua valorização, ela acredita estar acima da sociedade.

Do resultado do embate travado no Parlamento brasileiro, e que teve por objeto uma nova lei de biossegurança (lei 11.105/2005), verificou-se que, na prática, se chocavam duas concepções de progresso. De um lado, forjou-se uma aliança entre as transnacionais das chamadas "ciências da vida", o agronegócio e parte importante da comunidade científica para transformar a lei de biossegurança em lei de fomento à biotecnologia. Seu objetivo: instituir uma moldura jurídica que não pusesse limite algum à pesquisa e à comercialização da engenharia genética. Seu principal argumento: qualquer entrave à ativi-
[3] U. Beck. Risk society - towards a new modernity. Londres: Sage, 1992; B. Adam, U. Beck, U. e J. Van Loon (orgs.).The risk society and beyond: critical issues for social theory. Londres: Sage, 2000; J. Van Loon. Risk and technological culture. International Library of Sociology. Londres/Nova York: Routledge, 2002; H. Martins. Technology, the risk society and post-history. Lisboa: Instituto Superior de Ciências Sociais e Políticas, 1996; "Risco, incerteza e escatologia Reflexões sobre o experimentum mundi tecnológico em curso". Episteme, ano $1, \mathrm{n}^{\mathrm{O}}{ }_{1}$, Lisboa, Centro de Estudos de Epistemologia e História das Ciências e das Técnicas, dez. 1997-jan. 1998; e "Aceleração, progresso e experimentum humanum". In: H. Martins e J. L. Garcia (orgs.). Dilemas da civilização tecnológica. Lisboa: Imprensa das Ciências Sociais, 2003, pp. 1-61; P.Virilio. Velocidade e política. São Paulo: Estação Liberdade, 1996.

[4] Como ficou evidente para qualquer observador das Conferências das Partes da Convenção sobre Diversidade Biológica ao longo dos anos 1990. 
[5] Bastaria enumerar aqui seis pontos do último relatório da FAO, celebrado pela imprensa brasileira como "prova" de que os alimentos transgênicos são seguros somente porque se afirma que eles poderiam ajudar a resolver o problema da fome no mundo: 1 . Maior esforço em pesquisa é necessário, porque muito poucos OGMs foram avaliados em seus impactos ecológicos em regiões tropicais. 2. Marcos regulatórios devem ser reforçados e racionalizados para assegurar que o meio ambiente e a saúde pública sejam protegidos e que os procedimentos sejam transparentes, previsíveis e baseados na ciência. 3. A estratégia de manejo inclui evitar as culturas transgênicas em seus centros de diversidade ou onde houver espécies selvagens relacionadas ou estabelecer zonas-tampão entre as culturas. 4. Há consenso que a liberação no meio ambiente dos OGMs deve ser comparada com outras práticas agrícolas e opções tecnológicas. 5 . Não há ainda métodos de avaliação de impacto ambiental em nível internacional, sendo necessário estabelecer metodologias para os diferentes ecossistemas. 6. A falta de efeitos negativos observada até agora não significa que eles não possam ocorrer, tendo em vista o muito que permanece desconhecido. FAO, Agricultural biotechnology: meeting the needs of the poor? Roma, maio de 2004. dade tecnocientífica ou ao mercado constitui uma ameaça ao progresso e um obstáculo à realização da futura felicidade geral da nação. Seu mote: o Brasil tem pressa e precisa se desenvolver a qualquer preço. De outro lado, movimentos sociais organizados, ambientalistas e uma parcela minoritária da comunidade acadêmica e científica entendiam que uma lei de biossegurança deve existir para valer. Seu objetivo: proteger a sociedade e o ambiente dos riscos inerentes às novas tecnologias, e responsabilizar aqueles que porventura vierem a infringir a segurança da alimentação e da saúde da população brasileira. Seu principal argumento: não há evidência científica no mundo, e muito menos no Brasil, de que os efeitos de longo prazo da engenharia genética não sejam prejudiciais'; e, mesmo no curto e no médio prazos, seria preciso sair dos clichês generalizantes sobre o progresso e perguntar: Quem se beneficia com as opções tecnológicas que estão sendo feitas? Equem paga os custos social e ambiental que porventura se apresentarem? Seu mote: nem mesmo o imperativo do progresso prescinde de parâmetros - até porque um progresso no presente que possa comprometer o próprio progresso no futuro não poderia ser considerado como tal!

Não foi à toa que o foco do conflito criado em torno do projeto de lei de biossegurança se concentrou no sentido que se deve conferir ao princípio de precaução. $\mathrm{O}$ artigo $15^{\circ}$ da Convenção sobre Diversidade Biológica, da qual o Brasil é signatário, estipula que "Onde há risco de uma destruição séria ou irreversível, a falta de plena certeza científica não deveria ser usada como razão para postergar medidas efetivas que previnam a degradação ambiental". Por outro lado, o Protocolo de Cartagena, em vigor desde setembro de 2003 , afirma, em seu artigo $2^{\circ}$, inciso 2, que os países deverão assegurar o desenvolvimento, o manuseio, o transporte, o uso, a transferência e a liberação de qualquer organismogeneticamente modificado, levando em conta prevenir ou reduzir os riscos à diversidade biológica, considerando também os riscos à saúde humana. Para tanto, o Protocolo recomenda que a avaliação de riscos seja feita "caso a caso". Finalmente, o artigo 225 da Constituição brasileira de 1988 definiu o direito à biodiversidade, que, segundo Carlos Frederico Marés de Souza Filho, ao elevaro meio ambienteecologicamente equilibrado à categoria de bem jurídico e, portanto, juridicamente apropriável de forma coletiva, criou talvez o mais importante dos direitos coletivos. Como escreve o jurista:

Este direito quiçá seja o mais relevante porque vem assumindo um papel de destaque no mundo atual. O meio ambiente já interfere em vários institutos e subsistemas jurídicos tradicionais, alterando velhos dogmas do direito e até mesmo a relação dos cidadãos como Estado e com as empresas comerciais. [...] O texto garante a integridade do patrimônio genético do 
país, o que significa que qualquer ameaça de extinção de uma espécie deve resultarnuma intervenção do Estado com a finalidade de reporo equilibrio, criando espaços geográficos territoriais protegidos e limitando ou proibindo atividades nocivas ${ }^{6}$.

Tomando, portanto, em consideração todos esses marcos jurídicos já estabelecidos que consagram o princípio de precaução, o projeto de lei de biossegurança foi concebido de tal modo que especialistas, sociedade civil e governo pudessem compartilhar da elaboração e aplicação de regras que visem à proteção dos seres vivos, cabendo ao Estado, e não ao mercado, nem à tecnociência, a palavra final. Mesmo porque é ele quem deve responder pela coisa pública, e a biossegurança é uma questão de interesse público. Ora, isso se revelava intolerável tanto para a tecnociência quanto para o lobby das transnacionais e do agronegócio7.

Com efeito, a proposta governamental suscitou uma luta, tanto fora quanto dentro do próprio governo, pela conversão do princípio de precaução, que é a própria razão de ser da lei de biossegurança, em um ornamento retórico e num simulacro de respeito às convenções internacionais e à Constituição. Tal conversão dependeria do papel que a lei deve atribuir à Comissão Técnica Nacional de Biossegurança (CTNBio). Assim, o confronto se cristalizou em torno de duas perguntas: 1) Deve a CTNBio ter o poder de regular a pesquisa sobre alimentos geneticamente modificados, ou teria ela também o de autorizar a comercialização de transgênicos? 2) Proíbe-se ou não a pesquisa com células-tronco embrionárias humanas e com clonagem terapêutica? E deve a CTNBio ser a instância encarregada do assunto? Como se vê, no primeiro caso, a ênfase recai em uma questão de interesse primordialmente econômico e afeta, sobretudo, a agricultura; já no segundo, a relevância é de caráter prioritariamente tecnocientífico e afeta a saúde humana.

A rigor, e por uma questão de coerência, a pesquisa com célulastronco não deveria ser contemplada em uma lei de biossegurança, mas ser objeto de uma legislação específica - é, aliás, o que foi defendido pela Sociedade Brasileira para o Progresso da Ciência e por boa parte do grupo dos ambientalistas e dos movimentos sociais. Entretanto, a sua inserção indevida no projeto de lei aprovado pela Câmara dos Deputados em março de 2004 aproximou os interesses dos cientistas dos das transnacionais e do agronegócio ${ }^{8}$.

Para olobby dos ruralistas, caiu a sopa no mel, pois agora os cientistas passavam por cima da insuficiência dos estudos sobre a transgenia e ofereciam a sua colaboração para reforçar uma causa que não era inicialmente deles. Por outro lado, essa adesão suscitou uma polarização entre cientistas e ambientalistas que acentuou o preconceito segundo
[6] Carlos F. M. de Souza Filho. O renascer dos povos indígenas para $o$ direito. 2-ed. Curitiba: Juruá, 1999, p.181.

[7] Em um artigo interessantíssimo, Ingrid Sarti escreve: "Contrariando a lógica, não é exatamente sobre biossegurança o debate que se dá neste momento em torno do Projeto Nacional de Biossegurança, aprovado na Câmara há três meses, e agora transformado em obscuro objeto de disputa em tramitação no Senado. [...] é outro o x do problema. [...] São, porém, os aspectos de natureza econômica embutidos na lei que, desde a etapa do debate na Câmara, fizeram do confronto de interesses uma disputa típica de um autêntico Fla x Flu. A polêmica reúne setores aliados do agronegócio e de pesquisadores da área da genética molecular que trabalham no desenvolvimento de organismos transgênicos contra os ambientalistas. Basicamente, e em poucas palavras, por que o Plano Nacional de Biossegurança preserva o aspecto que é fundamental para o princípio de precaução: o rigor para as liberações comerciais. [...] Investimentos e garantias de agilidade em todo o processo de pesquisa, rigor nos pareceres técnicos e transparência nas escolhas políticas que determinam em última instância a oportunidade de comercialização de um produto são questões fundamentais para o desenvolvimento da ciência, que não se esgotam, porém, no processo legislativo. Que nele sejam contempladas é, no entanto, um ponto de partida de um governo que projeta uma política de ciência para a cidadania". "Biossegurança não é a questão", JC e-mail 2531, 25 de maio de 2004, divulgado pela rede eletrônica Ghente, da Fundação Oswaldo Cruz, Rio de Janeiro.

[8] O veto às pesquisas foi introduzido à última hora por ocasião da votação do projeto de lei de biossegurança na Câmara dos Deputados, em 5 de fevereiro de 2004. Incluído para atender aos interesses das bancadas evangélica e católica, recebeu fortes críticas da comunidade científica. $\mathrm{O}$ artigo $5^{\circ}$ do projeto aprovado na Câmara diz o seguinte: "É vedado: I - qualquer procedimento de engenharia genética em organismos vivos ou o manejo in vitro de DNA/RNA natural ou recombinante, realizado em desacordo com as normas previstas nesta Lei; II - 
manipulação genética em células germinais humanas e em embriões humanos; III - clonagem humana para fins reprodutivos; IV - produção de embriões humanos destinados a servir como material biológico disponível; $\mathrm{V}$ - intervenção em material genético humano in vivo, exceto se aprovado pelos órgãos competentes para fins de: a) realização de procedimento com finalidade de diagnóstico, prevenção e tratamento de doenças e agravos; b) clonagem terapêutica com células pluripotentes".

[9] Em suas considerações finais sobre a questão das plantas transgênicas no Brasil, Carmen Luiza Cabral Marinho escreve, a respeito da CTNBio: "Até hoje não foi elaborada a Política Nacional de Biossegurança, uma das atribuições da CTNBio, conforme determinou a Lei de Biossegurança [de 1995]. Carece-se de instruções normativas concernentes, entre outros aspectos, à fiscalização, aos recursos financeiros e humanos necessários, bem como às dimensões aceitáveis das áreas para liberação experimental. Entretanto, mesmo na ausência de diretrizes claras, foram concedidas liberações com OGMs no meio ambiente, em áreas cuja extensão varia de 0,006 a 110 hectares para um mesmo transgênico e com idêntica finalidade. É impossível deduzir quais critérios científicos justificariam tal disparidade. Decisões igualmente irresponsáveis encontram-se nas várias liberações de experimentos para 'fins de demonstração', chegando uma mesma concessão a contemplar mais de quarenta diferentes fazendas particulares. Desse cenário caótico, emerge uma total desconexão entre o trabalho das diversas instâncias envolvidas com a questão da biossegurança dos transgênicos no país. Os ministérios eximiam-se da fiscalização e assistiam, sem intervir, às constantes liberações por parte da CTNBio. Por outro lado, a Comissão, mesmo ciente da ausência de fiscalização, prosseguia nas autorizações para experimentos no meio ambiente". $O$ discurso polissêmico sobre plantas transgênicas no Brasil: Estado da arte. Tese de doutorado em Ciências, área de Saúde Pública, Escola Nacional de Saúde Pública, Rio de Janeiro, 2003.

[10] Em 17 de fevereiro de 2004, sociedades e entidades científicas brasileiras endereçaram aos senadores uma Carta Aberta relativa ao projeto de lei o qual a defesa do meio ambiente é "arcaica", "retrógrada" e "antiprogresso". Uma polarização equivocada, se pensarmos que os defensores do princípio de precaução reivindicavam mais estudos científicos a respeito do impacto das novas tecnologias. Finalmente, como na época do fascismo, os promotores das mais modernas tecnologias acabaram de mãos dadas com os segmentos mais conservadores da sociedade - é o avanço tecnológico turbinando a regressão social.

Tudo se passa como se a parcela de cientistas que cerraram fileiras atrás da Associação Nacional de Biossegurança - em defesa de uma lei que assegurasse a autonomia total da CTNBio - não quisesse uma lei separada para regular a pesquisa com células-tronco, porque viu com "pragmatismo" a possibilidade de trocar o apoio à comercialização dos transgênicos contra o apoio à aprovação de seus projetos. Entretanto, conviria observar que a aliança com o lobby dos ruralistas teve uma série de implicações para os cientistas. Com efeito, estes precisavam fazer vista grossa não só sobre a ausência de estudos científicos a respeito do impacto ambiental da soja transgênica no Brasil, mas também sobre as muitas práticas ilegais que foram cometidas nos últimos anos, por ocasião da introdução de sementes transgênicas no país - contrabando planejado, plantio clandestino, desrespeito à legislação e a decisões judiciais, propaganda enganosa e, last but not least, abuso de poder da CTNBios. Práticas que, aliás, a bem da verdade, foram inocentadas e premiadas por uma legislação de exceção, medidas provisórias providenciais de FHC e de Lula, em escandalosas declarações públicas de que o crime compensa, eque, posteriormente, cientistas e ruralistas pretenderam sacramentar, através da homologação de todas as decisões anteriores daquela comissão, o que inclui a liberação da soja RR da Monsanto. No açodamento de tornar irreversíveis determinadas opções dentro da engenharia genética não faltaram nem mesmo assinaturas forjadas na Carta Aberta que as sociedades e entidades científicas lideradas pela Associação Nacional de Biossegurança endereçaram aos senadores para pressionar... ${ }^{10}$.

Aconduta dos cientistas no episódio da aprovação da lei de biossegurança suscita, portanto, algumas indagações que expressam a parcialidade de seu "espírito científico". Pois cabe perguntar: Por que a comunidade científica não se pronunciou enquanto tal a respeito das ilegalidades que foram cometidas ao longo dos últimos anos para criar o fato consumado da soja transgênica no Brasil? Por que não se fez um estudo objetivo dos estudos da Monsanto sobre a soja transgênica? Por que não exigiu uma discussão de fundo sobre as vantagens comparativas de um e outro tipo de plantio que abarcasse toda a complexidade que o tema exige? Por que não se manifestou publicamente quando o Banco Nacional de Desenvolvimento Econômico e Social premiou a Monsanto, concedendo-lhe 40 milhões de dólares para 
beneficiar uma fábrica de glifosato em Camaçari, fábrica esta que já havia sido construída com um financiamento do Fundo de Investimento do Nordeste de 225 milhões de reais em dezembro de 1999, o que significava mais de $60 \%$ do orçamento total do Finor para 2000 ? Elogo o glifosato, esse agrotóxico tão polêmico, que levou a Monsanto a solicitar à Agência Nacional de Vigilância Sanitária que ampliasse de 0,2 mg/kg para $10 \mathrm{mg} / \mathrm{kg}$ o limite máximo de resíduos permitido em grãos de soja, isto é, um aumento de cinqüenta vezes? E por que não cobrou que a Anvisa disponibilizasse os estudos apresentados pela Monsanto sobre o glifosato em sua "consulta pública"? Finalmente, como observa a pesquisadora Sônia Barroso, "Por que os lobistas não informam seus financiamentos de pesquisa? Por que não se discute o Código de Ética e Controle das Pesquisas Biotecnológicas? Por que o processo de negociação da aprovação das leis não é feito com a informação de todos os dados, como, por exemplo, a contaminação de culturas não-transgênicas ocorrida no Paraná?"11.

É interessante observar que, se por um lado os cientistas se calaram em tantas ocasiões, por outro fizeram coro com os ruralistas que queriam restringir a representação da sociedade civil na CTNBio, argumentando que ONGs e entidades de defesa do consumidor não deveriam poder ter assento na comissão mesmo que indicassem cientistas... uma vez que estes poderiam ser "parciais" e "não objetivos". Em defesa de uma perspectiva puramente científica e técnica, os cientistas pressupunham, portanto, que a opção mais conveniente para a tecnociência é a mais adequada para a sociedade como um todo. Além disso, cientistas e empresários ruralistas não queriam que os ministérios, e principalmente o Ministério do Meio Ambiente, pudessem dispor de qualquer instância de tomada de decisão. Assim, enquanto em alguns países europeus são constituídos comitês que reúnem todos os setores interessados nas opções tecnológicas para discuti-las antes que se tome uma decisão política, no Brasil achamos um escândalo que a sociedade civil queira e possa participar...

Fica evidente, então, a necessidade de levantar o papel que os biotecnólogos têm assumido no Brasil, tanto em sua não-relação com os povos indígenas e tradicionais quanto em sua relação negativa com os ambientalistas e os setores da sociedade civil, que querem participar das decisões referentes às opções tecnológicas. No primeiro caso porque a relação entre bio e sociodiversidade, por ser muito intensa e importante, não deveria ser eternamente ignorada, pois nossa negligência poderá nos custar muito caro; no segundo porque, se prevalecerem somente os interesses da tecnociência e do mercado, é preciso que a sociedade tenha instrumentos para responsabilizá-los, em caso de "efeitos colaterais" adversos. de biossegurança, na qual se pronunciam sobre quatro pontos: 1. Que a Comissão Técnica Nacional de Biossegurança seja a única e definitiva instância para julgar a natureza científica da matéria e que o parecer da CTNBio seja vinculante tanto para as atividades de pesquisa quanto para as de comercialização. 2. Quea CTNBio seja a única e definitiva instância para julgar a segurança dos produtos da ciência e da tecnologia no Brasil, cabendo ao Conselho Nacional de Biossegurança opinar sobre a pertinência socioeconômica da permissão de comercialização.3.Que sejam convalidados os atos já praticados pela CTNBio desde 1995 até esta data, independentemente de estarem relacionados à comercialização ou à pesquisa. 4. Que a CTNBio também seja considerada com legitimidade para decidir em última instância sobre as pesquisas com células-tronco embrionárias. Assinavam a Carta a Academia Brasileira de Ciências, a Associação Nacional de Biossegurança, a Associação Brasileira de Distrofia Muscular, a Associação Brasileira para a Proteção dos Alimentos, o Centro Brasileiro de Estocagem de Genes, o Centro de Estudos do Genoma Humano, a Sociedade Brasileira de Alimentação e Nutrição, a Sociedade Brasileira de Ciência e Tecnologia de Alimentos, a Sociedade Brasileira de Genética, a Sociedade Brasileira de Melhoramento de Plantas e a Sociedade Brasileira de Microbiologia. Posteriormente, a Sociedade Brasileira de Genética e a Sociedade Brasileira de Microbiologia desmentiram tê-la assinado. Também a Sociedade Brasileira de Ciência e Tecnologia de Alimentos não a teria subscrito, segundo seu ex-presidente Luiz Eduardo R. de Carvalho. Cf. "Carta de cientistas teve assinaturas forjadas", Folha de S.Paulo, 4 de março de 2004, e "Sociedade Brasileira de C\&T de Alimentos também não assinou documento sobre projeto de lei de Biossegurança, JC e-mail 2477, 5 de março de 2004 , retransmitido pela rede eletrônica Ghente, da Fundação Oswaldo Cruz, Rio de Janeiro.

[11] Cf. lista de discussão na rede eletrônica Ghente, 5 de maio de 2004. 
Recebido para publicação em 16 de julho de 2007 .

\section{NOVOS ESTUDOS}

CEBRAP

78 , julho 2007

pp. 49-57
Mas o ideal, mesmo, seria que os biólogos e biotecnólogos, em vez de se afastar, se aproximassem tanto dos povos indígenas quanto da sociedade civil; que, de certo modo, operando uma espécie de deslocamento da percepção e do enfoque, redescobrissem o Brasil, enfrentassem o desencontro ou o "malencontro" que parece marcar sua relação com a sócio e a biodiversidade. Sem o que nunca poderemos entender a diferença de fazer biotecnologia aqui e em qualquer outro lugar do planeta.

LAYMERT GARCIA DOS SANTOS é professor titular do Instituto de Filosofia e Ciências Humanas da Unicamp, doutor em Ciências da Informação e coordenador do grupo Conhecimento, Tecnologia e Mercado (CTeMe). Autor de Politizaras novas tecnologias (Editora 34, 2003), entre outros. 